\title{
Modelling daily precipitation features in the Volta Basin of West Africa
}

\author{
Patrick Laux $x^{1}$, Sven Wagner ${ }^{1}$, Harald Kunstmann ${ }^{1} \&$ András Bárdossy $^{2}$
Institute for Meteorology and Climate Research, Forschungszentrum Karlsruhe
}

${ }^{2}$ Institute for Hydraulic Engineering, University of Stuttgart, Germany

\section{Motivation}

The analysis of the monthly or annual precipitation amount does not provide any adequate information for agricultural sector in the Volta Basin. Therefore, rainfall modelling must be performed on a daily basis to account for the intra-seasonal rainfall distribution. As an example, the dry spells occurrences with durations of more than 6 days within the following month after planting are calculated, because they are essential for the survival of the plants (Laux et al., 2008A).

Important plant physiological needs are calculated and condensed to maps for agricultural decision support. These maps can assist farmers in their decision when, where and what to plant (Laux et al., 2008B).

\section{Methodologies}

- Markov chain model (zero and first order) and gamma distribution for modelling rainfall occurrence and rainfall amount

- Effective Drought Index (EDI) to derive important drought properties

- Copula approach to model drought events more realistic considering jointly drought duration and drought intensity

\section{Results}
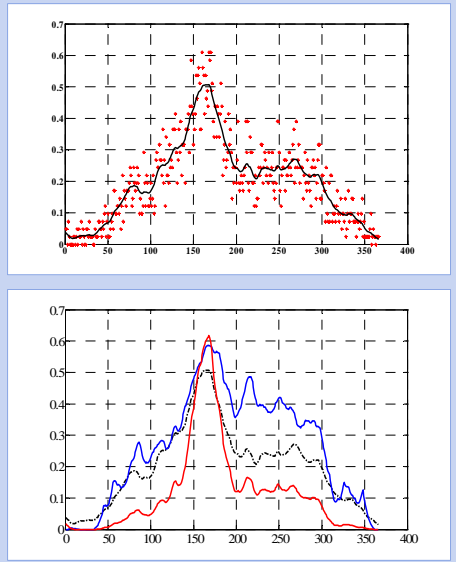

Fig. 1: Top: Overall rainfall probability (zero-order Markov model) for each day of the year at Accra, based on rainfall
data (1961-1999) with a hreshold of 1 m for a rany data (1961-1999) with a threshold of $1 \mathrm{~mm}$ for a rainy day,
observed $(*)$ and fitted fitted $(-)$ using Fourier series with four harmonics (top).

Bottom: $1^{\text {st }}$ order Markov chain of Accra. The red line stands for the fitted probability of rain, if it is followed by a dry day and the blue line for the fitted probability of rain, if it is followed by a wet day. The black line is depi
the fitted overall rainfall probability (for comparison).

a)

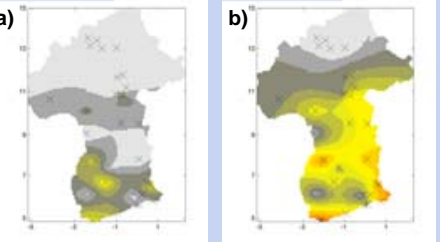

A clear seasonal cycle of the rainfall probabilities can be observed (Fig. 1). The overall chance of rain during the major rainy season (June) is approximately twice the rainfall probability during the minor rainy season (Sept/Oct.). Excepted for the peak of the major rainy season (around DOY 160), the probability of rain following a rainy (dry) day is greater (lower).
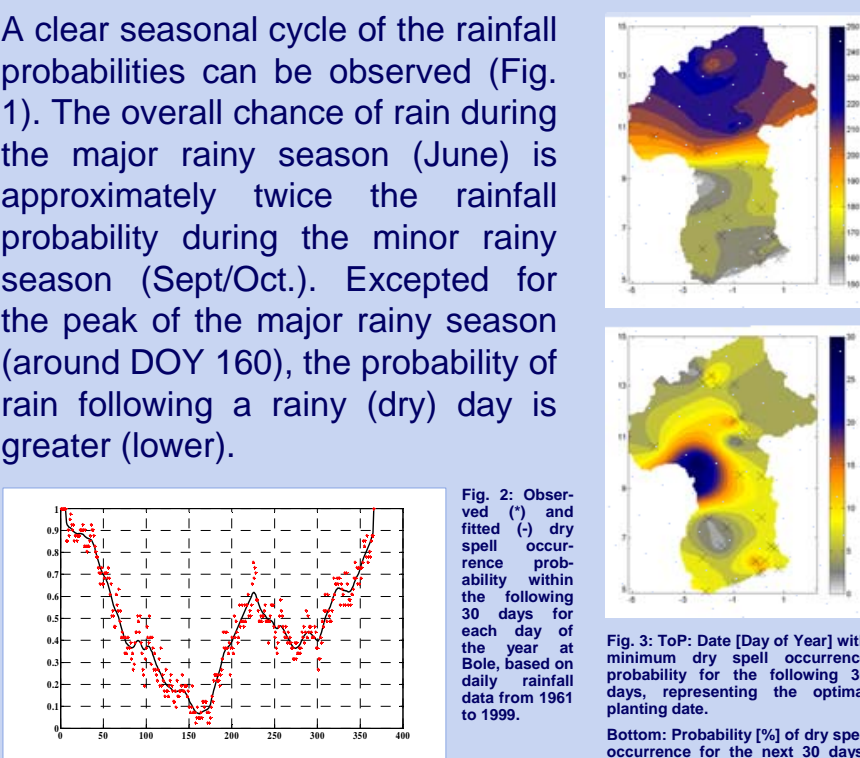

The dry spell occurrence probability and the date (DOY) is calculated for each station (e.g. illustrated for Bole, see Fig. 2). Both measures are interpolated using EDK. The obtained maps provide very important information for farmers about the best choice of the planting date to avoid total crop failure. In the north-western region of Ghana, planting should be started around DOY 150 , however, the probability of dry spell occurrence is $30 \%$.

Probabilities of rainfall exceeding $5 \mathrm{~mm}$ per day are calculated. The results are presented in condensed form for the months in which more than $95 \%$ of the rains fall (Fig. 4).

Fig. 3: ToP: Date [Day of Year] with Fig. 3: ToP: Date [Day orcurrence
minimum dry spell occiobility for the following 30 days, repres
planting date. Bottom: Probability [\%] of dry spell
occurrence for the next 30 days.
External drift kriging, including External drift kriging, including
distance-to-sea information, was
applied for spatial interpolation.
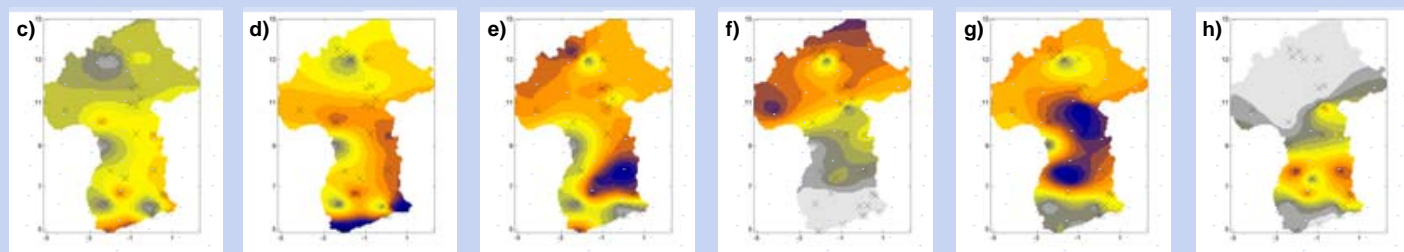

Fig. 4: Spatial distribution of rainfall occurrence

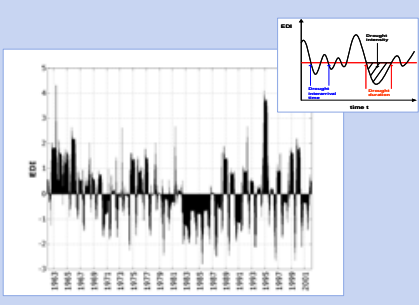

Based on the EDI time series (Fig. 5), drought intensity, drought duration and drought interarrival time are calculated for 5 different regions within the Volta Basin. Strong linear dependencies between drought duration (DD) and drought intensity (DI) can be found (Fig. 6). The events are accumulated in the lower marginals. A Clayton copula model is estimated to account for the joint distribution of DD and DI under consideration of the marginal distribution. On that basis, Fig. 5: Effective Drought Index (EDI) for regional drought return periods are derived.

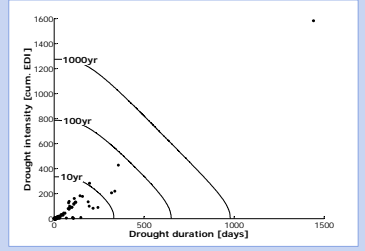

Fig. 6: Isolines of drought return periods in northern Burkina Faso. The dots represent the
past drought events (99 events from 1961-

\section{References}

Laux, P., Kunstmann, H. \& Bárdossy A. (2008A): Predicting the Regional Onset of the Rainy Season in West Africa; International Journal of Climatology, Vol. 28, issue 3, pp. 329-342. Laux, P., Wagner, S., Wagner, A., Kunstmann, H. \& Bárdossy A. (2008B): Modelling Daily Precipitation Features for the Volta Basin in West Africa; submitted to International Journal of Climatology. 